\title{
Conjugated Oligomers Containing Imidazole in Main Chain with Intramolecular Hydrogen Bonding
}

\author{
By Koji TAKAGI, * Kenta Sugihara, Junya OHTA, Yasuo YUKI, \\ Shin-ichi MATSUOKA, and Masato SUZUKI
}

\begin{abstract}
Conjugated oligomers containing imidazole or benzimidazole units were synthesized by Suzuki coupling polymerization of 4,5-dibromoimidazole or 4,7-dibromobenzimidazole with benzene-1,4-diboronic acid bearing a protected phenolic hydroxyl group and a decyloxy chain. The hydroxyl groups in the polymers were subsequently deprotected by catalytic hydrogenation with $\mathrm{Pd}-\mathrm{C} / \mathrm{H}_{2}$. As the content of the deprotected hydroxyl group increased, the UV absorption maximum wavelength in a THF solution red shifted. The PL emission maximum wavelength also red shifted and the fluorescence quantum yield decreased with increasing the degree of deprotection. Oligomers containing the imidazole unit demonstrated more pronounced shifts. For the imidazole-containing conjugated oligomer having the deprotected hydroxyl group, the UV and PL spectra blue shifted by increasing the solvent polarity. The addition of $\mathrm{NaOH}$ to a polymer solution gave rise to a blue-shift of the fluorescence peak. The UV and PL spectra showed ignorable shifts even when measuring in a thin film. These results could suggest that the imidazole-containing conjugated oligomer forms two intramolecular hydrogen bondings and has a nonplanar conformation.
\end{abstract}

KEY WORDS: Imidazole / Phenol / Conjugated Oligomer / Optical Property / Intramolecular Hydrogen Bonding / Conformation /

Conjugated polymers and oligomers are the most promising candidates as optoelectronic materials such as light-emitting diodes, ${ }^{1}$ field effect transistors, ${ }^{2}$ photovoltaic cells, ${ }^{3}$ and fluorescent chemical sensors. ${ }^{4}$ Compared to inorganic counterparts, their superior mechanical flexibility, which is the important nature for ubiquitous devices, strongly enhances the utility of polymeric materials. Since the chemical structure and molecular conformation determine the optoelectronic properties of materials, their fine-tuning must be highly important to obtain desirable functions. Among many conjugated polymers, those with basic nitrogen atoms offer the possibility of alkylation or protonation reactions as a way of modifying their properties. Thus conjugated polymers bearing pyridine moieties have been energetically investigated so far. ${ }^{5}$ On the other hand, imidazole, which has both of protonacceptable imine and proton-donating amine functionalities in the same aromatic ring, ${ }^{6}$ is of particular interest for the rich chemical reaction to enable the wide range of tailor-made modulation of the chemical structure and molecular conformation. We herein describe the synthesis and optical properties of imidazole-containing conjugated oligomers, which can form intramolecular hydrogen bonding. Although the intermolecular protonation of the benzimidazole ring involved in conjugated main chains with guest acids is well investigated, ${ }^{7}$ the formation of intramolecular hydrogen bonding including the imidazole ring is hitherto unknown. Bridging neighboring aromatic rings in the repeating unit with covalent and noncovalent bonds is proven to extend the effective $\pi$-conjugation and drastically affect the optoelectronic properties. ${ }^{8}$ When two kinds of intramolecular hydrogen bonding, i.e., 1) an imine

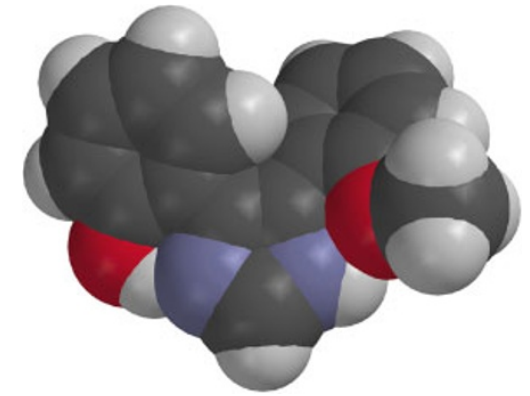

Figure 1. Space filling model around imidazole ring of molecule bearing two intramolecular hydrogen bondings, calculated by Spartan Essential v 1.0.6 (HF 3-21G method).

nitrogen with a phenolic hydroxyl proton and 2) an amino proton with an ether oxygen, are formed, the local conformation around the imidazole unit is forced to adopt a non-planar (curved) arrangement (Figure 1). The final goal of this research is to create a new family of hydrogen bonding-assisted ribbonlike conjugated foldamer. ${ }^{9}$

\section{EXPERIMENTAL}

\section{Materials}

All reactions were performed under nitrogen unless otherwise noted. Anhydrous diethyl ether (ether) and tetrahydrofuran (THF) were purchased from Aldrich and Kanto Chemical Co., respectively. Tetrakis(triphenylphosphine)palladium(0) $\left[\mathrm{Pd}\left(\mathrm{PPh}_{3}\right)_{4}\right]$ and palladium carbon (Pd-C) were purchased from TCI. ${ }^{\mathrm{n}} \mathrm{BuLi}$ was purchased from Kanto Chemical Co.

Department of Materials Science and Engineering, Graduate School of Engineering, Nagoya Institute of Technology, Gokiso-cho, Showa-ku, Nagoya 466-8555, Japan

*To whom correspondence should be addressed (Tel \& Fax: +81-52-735-5264, E-mail: takagi.koji@ nitech.ac.jp). 
Dichloromethane $\left(\mathrm{CH}_{2} \mathrm{Cl}_{2}\right)$, 1,2-dichloroethane $\left(\mathrm{ClCH}_{2} \mathrm{CH}_{2}\right.$ $\mathrm{Cl}$ ), and $\mathrm{N}, \mathrm{N}$-dimethylformamide (DMF) were dried over $\mathrm{CaH}_{2}$ and distilled under nitrogen prior to use. 4,5-Dibromo-2octylimidazole, ${ }^{10}$ 4,7-dibromo-2-octylbenzimidazole, ${ }^{11}$ and 2benzyloxy-5-decyloxybenzene-1,4-dibronic $\operatorname{acid}^{8 c}$ were synthesized according to the literature.

\section{Instrumentation}

${ }^{1} \mathrm{H}$ and ${ }^{13} \mathrm{C}$ nuclear magnetic resonance (NMR) spectra were recorded on a Bruker Avance 200 FTNMR spectrometer using tetramethylsilane ( $\left.{ }^{1} \mathrm{H} \mathrm{NMR}, \delta 0.00 \mathrm{ppm}\right)$ and $\mathrm{CDCl}_{3}$ $\left({ }^{13} \mathrm{C} \mathrm{NMR}, \delta 77.0 \mathrm{ppm}\right)$ or DMSO-d 6 ( $\left.{ }^{13} \mathrm{C} \mathrm{NMR}, \delta 39.7 \mathrm{ppm}\right)$ as internal reference peaks. Infrared (IR) spectra were recorded on a JASCO FT-IR 460Plus spectrophotometer in ATR method. Melting points $(\mathrm{Mp})$ were determined on a YANAGIMOTO micro melting point apparatus MP-J3. Gel permeation chromatographic (GPC) analyses were carried out on a Tosoh DP-8020 pump using tandem TSKgel $\mathrm{GMH}_{\mathrm{XL}}$ columns (THF as an eluent, flow rate $=1.0 \mathrm{~mL} / \mathrm{min}, 40{ }^{\circ} \mathrm{C}$ ) equipped with a refractive index detector (RI-8012) on the basis of standard polystyrene samples. Ultraviolet (UV) and photoluminescence (PL) spectra were recorded on a Shimadzu UV-1650PC spectrophotometer and a Shimadzu RF-5300PC spectrofluorometer, respectively, using a $1 \mathrm{~cm}$ quartz cell. Quantum yields in the solution were determined relative to quinine sulfate in $0.1 \mathrm{~N} \mathrm{H}_{2} \mathrm{SO}_{4}$ with a quantum yield of 0.55 .

\section{Polymerization of Hydroxyl Group-Protected Monomer}

(a) PImPh0: 4,5-Dibromo-2-octylimidazole (0.24 g, 0.70 mmol) and 2-benzyloxy-5-decyloxybenzene-1,4-dibronic acid $(0.30 \mathrm{~g}, 0.70 \mathrm{mmol})$ were dissolved in THF $(10 \mathrm{~mL})$ and $2 \mathrm{M}$ aqueous solution of $\mathrm{Na}_{2} \mathrm{CO}_{3}(2.8 \mathrm{~mL}) . \mathrm{Pd}\left(\mathrm{PPh}_{3}\right)_{4} \quad(8.1 \mathrm{mg}$, $7.0 \mu \mathrm{mol}$ ) was added and the solution was heated to reflux for 3 days under vigorous stirring. After cooling to room temperature, $\mathrm{CH}_{2} \mathrm{Cl}_{2}$ and $\mathrm{H}_{2} \mathrm{O}$ were added to shake in the separating funnel and the organic layer was separated. The aqueous layer was extracted a few times with $\mathrm{CH}_{2} \mathrm{Cl}_{2}$ and the combined organic phase was dried over $\mathrm{MgSO}_{4}$. The solution was concentrated to pour into $\mathrm{MeOH}$. The precipitate was collected and dried in vacuo to obtain a pale pink powder in $0.14 \mathrm{~g}(39 \%$ yield). ${ }^{1} \mathrm{H} \mathrm{NMR}\left(200 \mathrm{MHz}, \mathrm{CDCl}_{3}\right) \delta(\mathrm{ppm}) 10.31-9.82(1 \mathrm{H})$, 7.85-6.38 (7H), 5.28-4.21 (2H), 4.15-3.25 (2H), 2.81-2.37 (2H), 2.17-0.75 (34H). IR (ATR, $\mathrm{cm}^{-1}$ ) 3734, 3628, 3416, 2923, 2853, 1456, 1377, 1200, 1025, 866, 731, 694.

(b) PBImPh0: This oligomer was similarly prepared from 4,7-dibromo-2-octylbenzimidazole $(0.19 \mathrm{~g}, 0.50 \mathrm{mmol})$ and 2 benzyloxy-5-decyloxybenzene-1,4-dibronic acid $(0.21 \mathrm{~g}, 0.50$ $\mathrm{mmol})$ in $0.19 \mathrm{~g}\left(66 \%\right.$ yield). ${ }^{1} \mathrm{H} \mathrm{NMR}\left(200 \mathrm{MHz}, \mathrm{CDCl}_{3}\right) \delta$ (ppm) 7.89-5.85 (9H), 5.33-4.21 (2H), 4.17-2.75 (4H), 2.630.42 (34H). IR (ATR, cm ${ }^{-1}$ ) 3736, 3630, 3032, 2959, 2922, 2852, 1525, 1490, 1448, 1362, 1259, 1197, 1018, 797, 694.

\section{Deprotection of Hydroxyl Group}

(a) PImPh25: PImPh0 (0.04 g, $0.08 \mathrm{mmol}$ ) was dissolved in THF $(2.4 \mathrm{~mL})$ and EtOH $(2.4 \mathrm{~mL})$. After Pd-C (0.12 g) was added, the system was replaced with a hydrogen gas. Under the hydrogen atmosphere, the inhomogeneous mixture was stirred at room temperature for $1 \mathrm{~d}$ under vigorous stirring. The $\mathrm{Pd}-\mathrm{C}$ was filtered off with a celite pad and the filtrate was concentrated to pour into cold ${ }^{n}$ hexane. The precipitate was collected and dried in vacuo to obtain a pale yellow powder in 0.04 g. ${ }^{1} \mathrm{H}$ NMR (200 MHz, $\left.\mathrm{CDCl}_{3}\right) \delta$ (ppm) 10.47-9.79 (1H), $7.86-6.25(5.75 \mathrm{H}), 5.24-4.27(1.5 \mathrm{H}), 4.18-3.22(2 \mathrm{H}), 3.12-$ $2.38(2 \mathrm{H}), 2.06-0.67$ (34H). IR (ATR, $\left.\mathrm{cm}^{-1}\right) 3727,3627,3072$, 2923, 2853, 1634, 1494, 1464, 1416, 1281, 1200, 1020, 796, 721, 694.

(b) PImPh65: This oligomer was similarly prepared under the prolonged reaction time $(2 \mathrm{~d}) .{ }^{1} \mathrm{H}$ NMR $\left(200 \mathrm{MHz}, \mathrm{CDCl}_{3}\right)$ $\delta(\mathrm{ppm}) 10.44-9.19(1 \mathrm{H}), 7.78-6.19(3.75 \mathrm{H}), 5.29-4.31(0.7 \mathrm{H})$, 4.22-3.23 (2H), 3.11-2.34 (2H), 2.13-0.45 (34H). IR (ATR, $\left.\mathrm{cm}^{-1}\right) 3727,3628,3126,2922,2852,1635,1558,1492,1464$, 1415, 1281, 1200, 1014, 819, 796, 721.

(c) PBImPh35: This oligomer was similarly prepared by the catalytic hydrogenation with $\mathrm{Pd}-\mathrm{C} / \mathrm{H}_{2}$ from PBImPh0 under the reaction for $1 \mathrm{~d} .{ }^{1} \mathrm{H}$ NMR $\left(200 \mathrm{MHz}, \mathrm{CDCl}_{3}\right) \delta(\mathrm{ppm}) 8.15$ $5.93(7.25 \mathrm{H}), \quad 5.61-4.38(1.3 \mathrm{H}), 4.29-2.75(4 \mathrm{H}), 2.58-0.42$ (34H). IR (ATR, cm ${ }^{-1}$ ) 3727, 3632, 3033, 2922, 2852, 1525, 1490, 1447, 1362, 1260, 1197, 1024, 797, 694.

(d) PBImPh65: This oligomer was similarly prepared under the prolonged reaction time $(2 \mathrm{~d}) .{ }^{1} \mathrm{H}$ NMR $\left(200 \mathrm{MHz}, \mathrm{CDCl}_{3}\right)$ $\delta(\mathrm{ppm}) 8.23-5.85(5.75 \mathrm{H}), 5.19-4.45(0.7 \mathrm{H}), 4.33-2.73(4 \mathrm{H})$, 2.41-0.51 (34H). IR (ATR, cm $\left.{ }^{-1}\right) 3726,3628,3064,2955$, 2921, 2852, 1577, 1525, 1490, 1444, 1362, 1260, 1197, 1023, 799, 694.

\section{Model Compounds}

(a) BDIm (4-(o-benzyloxyphenyl)-5-(o-decyloxyphenyl)2-octylimidazole): 4,5-Dibromo-2-octylimidazole $(0.338 \mathrm{~g}$, $1 \mathrm{mmol})$ and 2-decyloxyphenylboronic $\operatorname{acid}^{12} \quad(0.278 \mathrm{~g}$, $1 \mathrm{mmol})$ were dissolved in THF $(20 \mathrm{~mL})$ and $2 \mathrm{M}$ aq. $\mathrm{Na}_{2} \mathrm{CO}_{3}$ $(4 \mathrm{~mL}) . \mathrm{Pd}\left(\mathrm{PPh}_{3}\right)_{4}(15.5 \mathrm{mg}, 10 \mu \mathrm{mol})$ was added and the solution was heated to reflux for $3 \mathrm{~d}$ under vigorous stirring. After cooling to room temperature, $\mathrm{CH}_{2} \mathrm{Cl}_{2}$ and $\mathrm{H}_{2} \mathrm{O}$ were added to shake in the separating funnel and the organic layer was separated. The aqueous layer was extracted a few times with $\mathrm{CH}_{2} \mathrm{Cl}_{2}$ and the combined organic phase was dried over $\mathrm{MgSO}_{4}$. The crude product was purified by $\mathrm{SiO}_{2}$ column chromatography $\left(\mathrm{CH}_{2} \mathrm{Cl}_{2}, \mathrm{Rf}=0.5\right)$ to obtain 4-bromo-5-(odecyloxyphenyl)-2-octylimidazole as a pale yellow solid in $0.34 \mathrm{~g}\left(69 \%\right.$ yield). ${ }^{1} \mathrm{H}$ NMR $\left(200 \mathrm{MHz}, \mathrm{CDCl}_{3}\right) \delta(\mathrm{ppm}) 10.05$ $(1 \mathrm{H}), 8.12(\mathrm{dd}, J=7.74 \mathrm{~Hz}, 1.22 \mathrm{~Hz}, 1 \mathrm{H}), 7.26(1 \mathrm{H}), 7.29$ $6.94(2 \mathrm{H}), 4.06(\mathrm{t}, J=6.43 \mathrm{~Hz}, 2 \mathrm{H}), 2.72(\mathrm{t}, J=7.71 \mathrm{~Hz}, 2 \mathrm{H})$, $1.91-1.25(28 \mathrm{H}), 0.90-0.85(6 \mathrm{H})$. Subsequently, 4-bromo-5-(odecyloxyphenyl)-2-octylimidazole $(0.176 \mathrm{~g}, 0.358 \mathrm{mmol})$ was condensed with 2-benzyloxyphenylboronic acid ${ }^{13}(0.204 \mathrm{~g}$, $0.895 \mathrm{mmol})$ using $\mathrm{Pd}\left(\mathrm{PPh}_{3}\right)_{4}(4.16 \mathrm{mg}, 3.6 \mu \mathrm{mol})$. The reaction and purification were performed in a similar manner to those of 4-bromo-5-(o-decyloxyphenyl)-2-octylimidazole to obtain a target compound as a pale purple solid in $0.175 \mathrm{~g}$ ( $82 \%$ yield). ${ }^{1} \mathrm{H}$ NMR $\left(200 \mathrm{MHz}, \mathrm{CDCl}_{3}\right) \delta(\mathrm{ppm}) 9.98(1 \mathrm{H}), 7.54-6.82$ $(13 \mathrm{H}), 4.99(2 \mathrm{H}), 3.81(2 \mathrm{H}), 2.73(2 \mathrm{H}), 1.97-0.78$ (34H). IR 


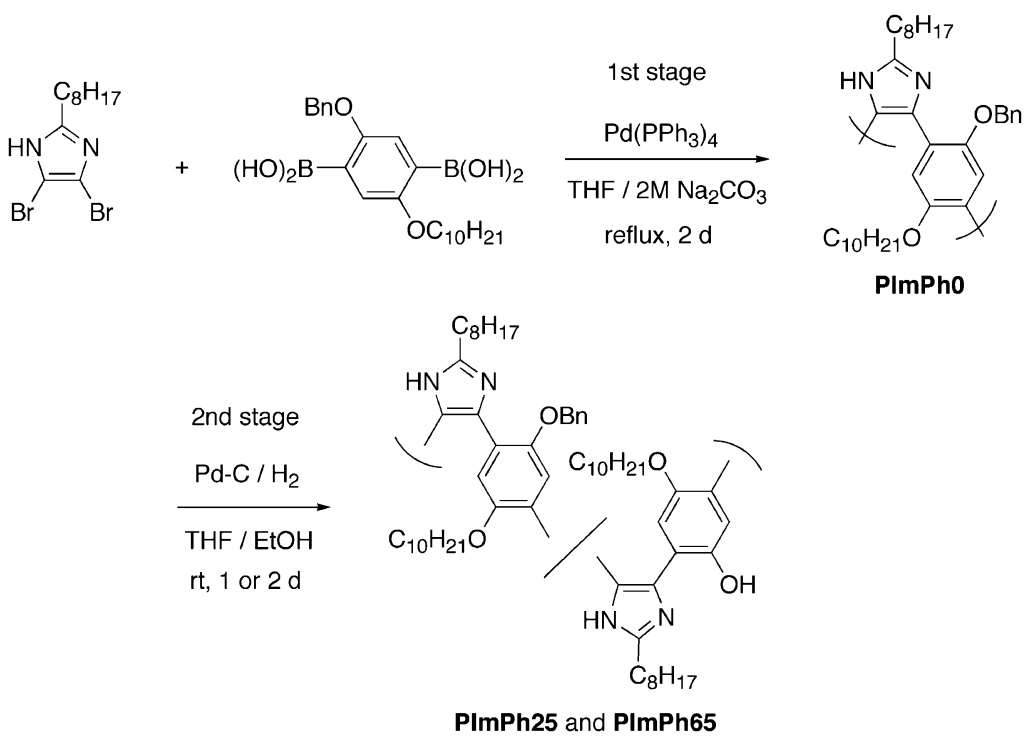

Scheme 1. Synthetic route of imidazole-containing conjugated oligomers.

(ATR, $\mathrm{cm}^{-1}$ ) 3646, 3435, 3030, 2923, 2853, 1579, 1529, 1498, 1455, 1378, 1280, 2137, 1121, 1022, 746.

(b) HDIm (4-(o-hydroxylphenyl)-5-(o-decyloxylphenyl)-2octylimidazole): BDIm $(0.08 \mathrm{~g}, 0.14 \mathrm{mmol})$ was dissolved in EtOH $(4 \mathrm{~mL})$. After Pd-C $(0.21 \mathrm{~g})$ was added, the system was replaced with a hydrogen gas. Under the hydrogen atmosphere, the inhomogeneous mixture was stirred at room temperature for 3 days under vigorous stirring. The $\mathrm{Pd}-\mathrm{C}$ was filtered off with a celite pad and the filtrate was concentrated to pour into cold ${ }^{\mathrm{n}}$ hexane. The precipitate was collected and dried in vacuo to obtain a brown solid in $0.02 \mathrm{~g}$ (32\% yield). ${ }^{1} \mathrm{H}$ NMR $\left(200 \mathrm{MHz}, \mathrm{CDCl}_{3}\right) \delta(\mathrm{ppm}) 13.5(1 \mathrm{H}), 7.62-6.61(8 \mathrm{H}), 3.85$ (2H), 2.86 (2H), 2.19-0.79 (34H). IR (ATR, cm ${ }^{-1}$ ) 3726, 3707, 3625, 3600, 3059, 2923, 2853, 1639, 1582, 1552, 1489, 1451, 1357, 1252, 1164, 1121, 1043, 830, 749.

\section{RESULTS AND DISCUSSION}

\section{Preparation}

Suzuki coupling polymerization of 4,5-dibromo-2-octylimidazole and 2-benzyloxy-5-decyloxybenzene-1,4-dibronic acid was performed to obtain PImPh0 bearing a protected hydroxyl group (Scheme 1, 1st stage). The number-averaged molecular weight $\left(M_{\mathrm{n}}\right)$ and the polydispersity index (PDI) were 4300 and 1.3, respectively, which approximately corresponded to 7 repeating units. The limited molecular weight of PImPh0 might be attributable to the low activity of the palladium catalyst. Since the imidazole ring has a potential ability to coordinate to the palladium center similarly to phosphine ligands and also the molar concentration of the imidazole unit is much higher than that of the palladium metal (imidazole: $\mathrm{Pd}=100: 1$ in the present system), the oxidative addition of $\operatorname{Pd}(0)$ species to 4,5-dibromo-2-octylimidazole is supposed to be hampered which decreases the over all reaction rate. The use of boronic acid derivative may be another reason to obtain
PImPh0 with the low molecular weight since the deboronation reaction of acids is reported to limit the production of high molecular weight polymers in $\mathrm{Pd}\left(\mathrm{PPh}_{3}\right)_{4}$-catalyzed Suzuki polycondensations. ${ }^{14}$ The steric hindrance of two bromides could be ruled out because Suzuki coupling polymerization of 4,7-dibromo-2-octylbenzimidazole with 2-benzyloxy-5-decyloxybenzene-1,4-dibronic acid also yielded the low molecular weight PBImPh0 (vide infra).

While the imidazole-based dibromo monomer is bilaterally symmetric by the proton transfer (tautomerization) within the ring, the diboronic acid monomer is asymmetric owing to the presence of two different substituents, i.e., decyloxy and benzyloxy chains, at their ortho position. Since the difference of the reactivity of two boronic acids is small, they probably coupled at 4 and 5 position of the imidazole ring in a statistic fashion. We can then find three local chemical structures depending on the ether substituent sandwiching the imidazole moiety. The first structure includes the imidazole unit facing two decyloxy chains, the second one has two benzyloxy chains, and the third one has each decyloxy and benzyloxy chains. In contrast to imidazole derivatives without substituent or with same groups at 4 and 5 positions, tautomerization isomers of these imidazole units are spectroscopically nonequivalent due to the locked proton transfer by the intramolecular hydrogen bonding in PImPho. Both an amino proton signal at ca. $10.1 \mathrm{ppm}$ and a methylene proton signal adjacent to the imidazole ring at $c a$. $2.6 \mathrm{ppm}$ obviously split into two peaks in the ${ }^{1} \mathrm{H}$ NMR spectrum of PImPh0 (Figure 2, up). Namely, the formation of two types of 6-membered intramolecular hydrogen bonding is possible between an amino proton and an ether oxygen as illustrated in Figure 3. Thus the relative coupling direction of two monomer components, hereafter termed as regioregularity, in the repeating unit in $\mathbf{P I m P h 0}$ was found to be random. For the simplification, only the representative chemical structure is shown in the present paper. 
up
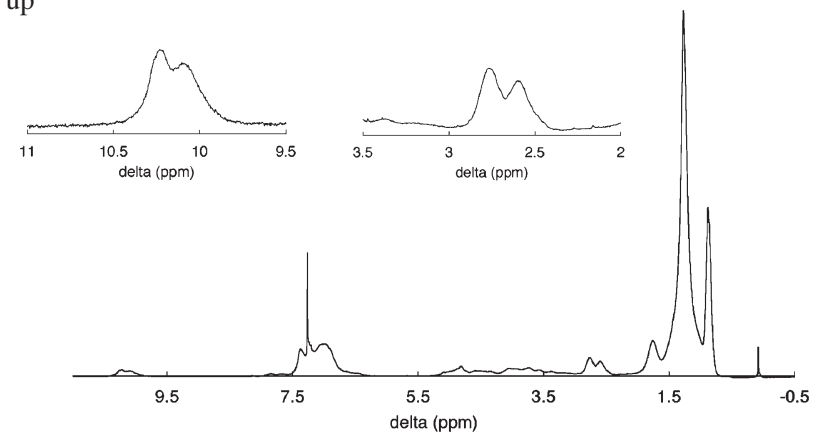

down

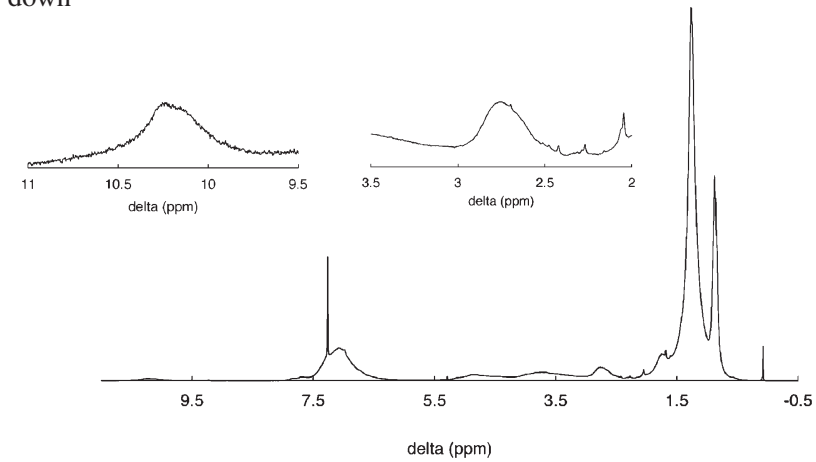

Figure 2. ${ }^{1} \mathrm{H}$ NMR spectra of PImPho (up) and PImPh25 (down) in $\mathrm{CDCl}_{3}$ at $40^{\circ} \mathrm{C}$ (Insets show the magnified views from $2 \mathrm{ppm}$ to $3.5 \mathrm{ppm}$ and from $9.5 \mathrm{ppm}$ to $11 \mathrm{ppm})$.
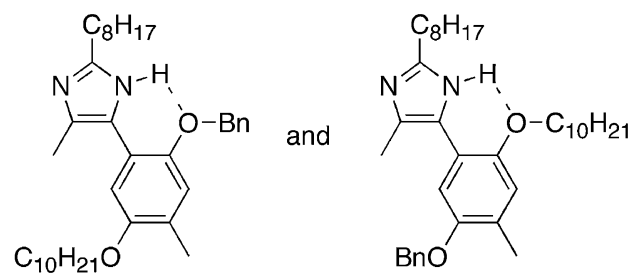

Figure 3. Two types $\mathrm{N}-\mathrm{H} \cdots \mathrm{O}-\mathrm{R}$ intramolecular hydrogen bonding in PImPh0.

The deprotection of the hydroxyl group was carried out by catalytic hydrogenation in the mixed solvent of $\mathrm{THF} / \mathrm{EtOH}$ (1:1 in volume) using $\mathrm{Pd}-\mathrm{C} / \mathrm{H}_{2}$ at room temperature according to the literature (Scheme 1, 2nd stage). ${ }^{15}$ The reaction for $1 \mathrm{~d}$ and $2 \mathrm{~d}$ afforded the corresponding oligomers bearing the phenolic hydroxyl group of $25 \mathrm{~mol} \%$ (PImPh25) and $65 \mathrm{~mol} \%$ (PImPh65), respectively. The hydroxyl group content was calculated from the integral ratio of methylene proton signals adjacent to the imidazole ring $(2.6 \mathrm{ppm})$ and of benzyl group (4.8 ppm) in the ${ }^{1} \mathrm{H} \mathrm{NMR}$ spectrum. In PImPh25 and PImPh65, an amino proton signal and a methylene proton signal adjacent to the imidazole ring became broad single peak (Figure 2, down). PImPh25 and PImPh65 were somewhat less soluble as compared with PImPh0, but the solubility of these oligomers was enough to dissolve in $\mathrm{CHCl}_{3}, \mathrm{CH}_{2} \mathrm{Cl}_{2}$, THF, and toluene. The difference of solubility may be a consequence of the formation of 6-membered intramolecular hydrogen bonding between an imine nitrogen of the imidazole unit and a hydroxyl proton of the phenol unit. The twist between the imidazole and phenyl rings in PImPho is released and the oligomer chains become more rigid (but non-planar) in PImPh25 and PImPh65. The polar character of the resulting materials might be also the origin of the solubility change. The hydroxyl proton signal in the ${ }^{1} \mathrm{H} N M R$ spectrum and the $\mathrm{C}=\mathrm{N}$ stretching vibration signal in the IR spectrum could not be observed clearly. Hence the presence of intramolecular hydrogen bonding was confirmed by the ${ }^{1} \mathrm{H}$ NMR spectra of model compounds, which were prepared by the repetitive Suzuki coupling reactions and following cleavage of the benzyl group. The deprotection of the hydroxyl group of the low molecular weight BDIm completely proceeded to give HDIm. By deprotecting the hydroxyl group, methylene proton signals adjacent to the imidazole ring and oxygen atom downfield shifted by $0.13 \mathrm{ppm}$ and $0.04 \mathrm{ppm}$, respectively. These shifts indicate the formation of two intramolecular hydrogen bondings around the imidazole unit (Figure 4). The intramolecular hydrogen bonding between a phenolic hydroxyl proton and an imine nitrogen is supposed to promote another hydrogen bonding between an amino proton and an ether oxygen.

Likewise, PBImPh0, PBImPh35, and PBImPh65 having the benzimidazole moiety were successfully prepared by the combination of Suzuki coupling polymerization between 4,7dibromo-2-octylbenzimidazole and 2-benzyloxy-5-decyloxybenzene-1,4-dibronic acid and the following polymer reaction (Scheme 2). The number-averaged molecular weight $\left(M_{\mathrm{n}}\right)$ was around 3500, which approximately corresponded to 6 repeating units. Again, the regioregularity of oligomer was random as confirmed by the ${ }^{1} \mathrm{H}$ NMR spectra. The phenol content was calculated from the integral ratio of three kinds of methylene proton signal in the ${ }^{1} \mathrm{H}$ NMR spectrum. Unfortunately, the longer reaction periods ( $c a .1$ week) and the elaborate screening of solvents in order to increase the phenol content

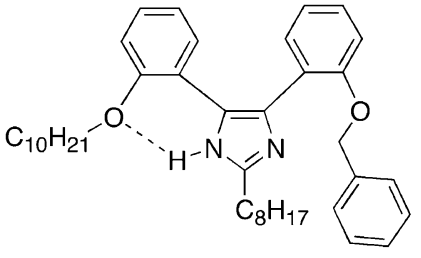

BDIm (one hydrogen bonding)

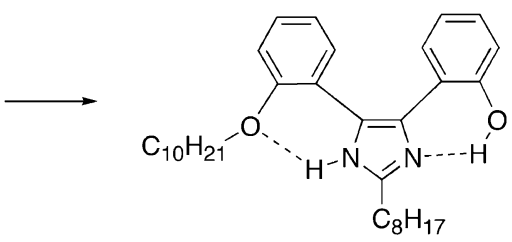

HDIm (two hydrogen bondings)

Figure 4. Intramolecular hydrogen bondings in model compounds. 

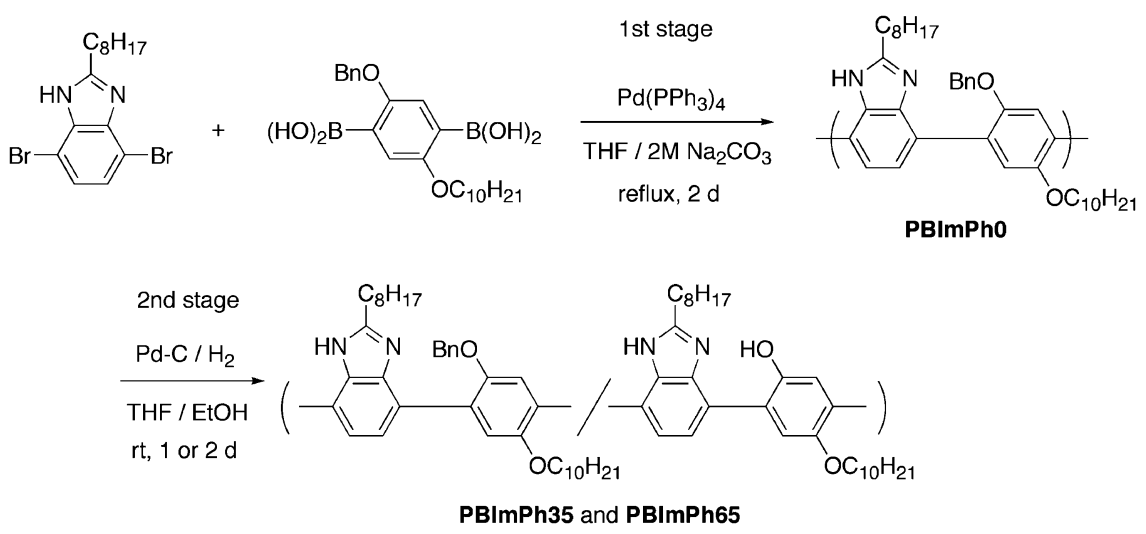

Scheme 2. Synthetic route of benzimidazole-containing conjugated oligomers.

met with no success for both series. Although a few drops of concentrated hydrochloric acid to the reaction mixture may dramatically improve the deprotection efficiency, ${ }^{15}$ the addition of protic acids brings about another problem. That is, the imine group is protonated and it is difficult to isolate absolutely neutral products. Thus other efficient techniques to quantitatively cleave the benzyl group are now under pursuit.

\section{Optical Properties}

The UV and PL spectra of PImPh0 without the hydroxyl group were measured in a THF solution $\left(10^{-5} \mathrm{M}\right)$. The absorption and emission maximum wavelengths of PImPh0 were $364 \mathrm{~nm}$ and $441 \mathrm{~nm}$, respectively, which unexpectedly showed bathochromic shifts as compared with PBImPh0 $(\lambda \mathrm{abs}=349 \mathrm{~nm}$ and $\lambda \mathrm{em}=419 \mathrm{~nm})$ bearing the same protected hydroxyl group. The quantum yield of PImPh0 (0.40) was lower than that of PBImPh0 (0.56). Initially, we anticipated that PBImPh0 had a longer effective conjugation length than PImPh0 because there must be a significant steric hindrance between two phenyl rings substituted at 4 and 5 positions of the imidazole ring. Additionally, the benzimidazole ring $(\mathrm{p} K \mathrm{a}=12.6)$ has a more acidic amino proton compared to the imidazole ring $(\mathrm{pKa}=14.1)$, which contributes the smooth formation of intramolecular hydrogen bonding with the ether oxygen in PBImPh0 to lead to the longer effective conjugation length. Judging from the UV and PL spectra, however, PImPho was found to have a wider $\pi$ conjugated system. The intramolecular hydrogen bonding formed in PImPh0 consists of thermodynamically favorable 6-membered ring (Figure 5, right), which is the plausible factor to afford locally near-planar conformation and red-shifted spectra of PImPho.

By deprotecting the phenolic hydroxyl group, both the UV and PL spectra gradually red shifted, that is, the absorption and emission maximum wavelengths of PImPh65 were observed at $372 \mathrm{~nm}$ and $458 \mathrm{~nm}$, respectively (Figure 6). The fluorescent quantum yield decreased from 0.40 (PImPh0) to 0.09 (PImPh65). These bathochromic shifts $(8 \mathrm{~nm}$ in UV and $17 \mathrm{~nm}$ in PL) may be due to the formation of intramolecular hydrogen bonding between the imine nitrogen and the phenolic hydroxyl proton and the change of electronic state of the main

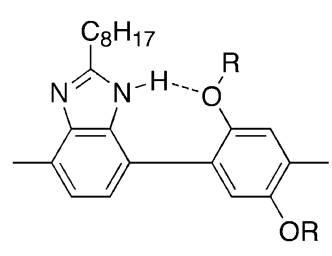

PBImPho (7-membered)

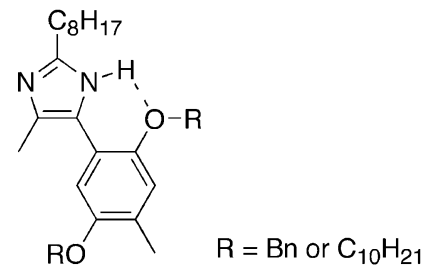

PImPho (6-membered)

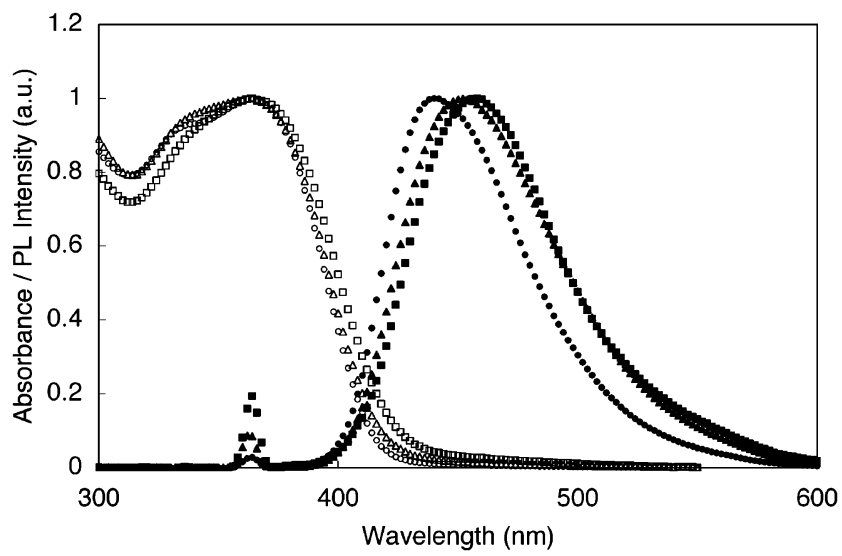

Figure 6. UV and PL spectra in THF solution $\left(10^{-5} \mathrm{M}\right)$. Opened circle: UV of PImPh0, closed circle: PL of PImPh0, opened triangle: UV of PImPh25, closed triangle: PL of PImPh25, opened square: UV of PImPh65, and closed square: PL of PImPh65.

chain $\pi$-conjugation, as observed in other previous papers. ${ }^{8}$ On the other hand, there was no detectable red-shift in the PL spectrum of PBImPh65 from that of PBImPh0 having the benzimidazole moiety. Since the intramolecular hydrogen bonding formed consists of 6-membered ring in the case of PImPh65, the spectrum shifts are more drastic and the longer wavelength emission is observed. The synergetic effect of two intramolecular hydrogen bondings might be responsible for the larger spectrum shift (see, Figure 4).

In the present work, the regioregularity is not controlled and the deprotection of the hydroxyl group is incomplete, so the intramolecular hydrogen bonding cannot be formed quantita- 

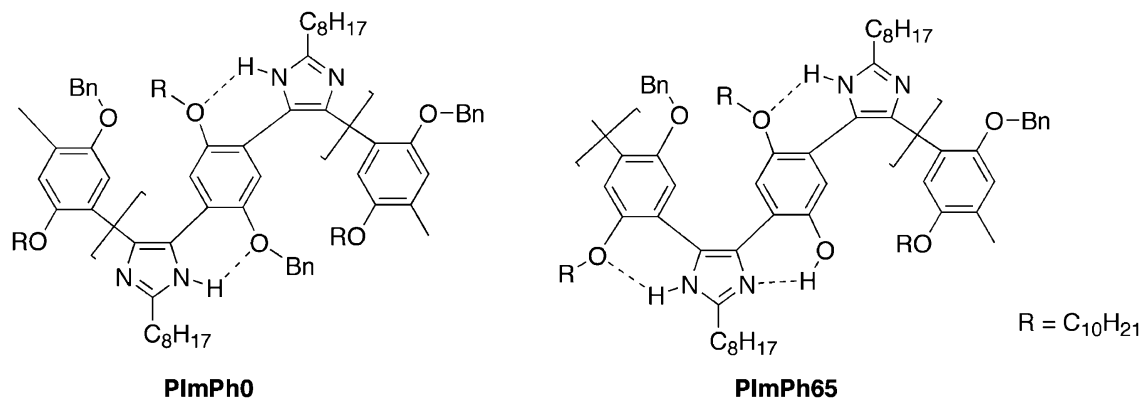

Figure 7. Schematic image of intramolecular hydrogen bonding (Parenthesis denotes the range of maximum $\pi$-conjugation).

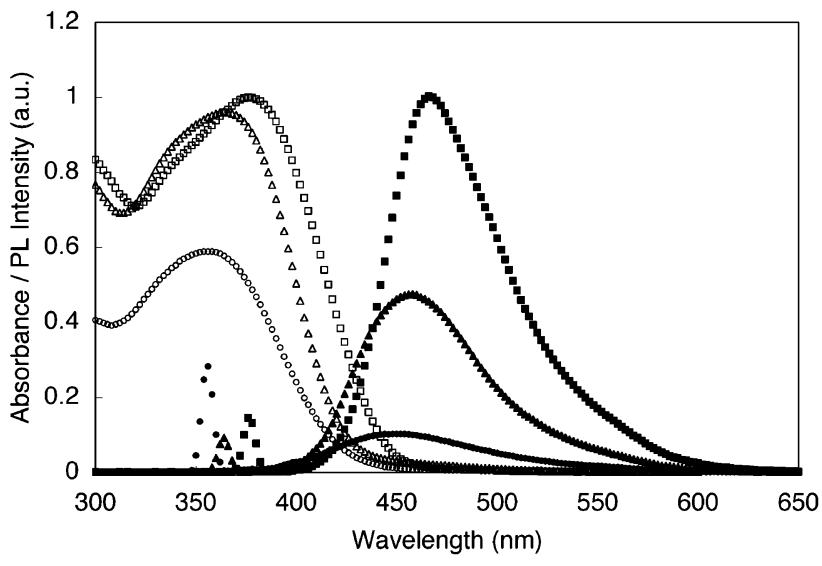

Figure 8. UV and $\mathrm{PL}$ spectra of PImPh65 in various solvents $\left(10^{-5} \mathrm{M}\right)$. Opened circle: UV in DMF, closed circle: PL in DMF, opened triangle: UV in THF, closed triangle: PL in THF, opened square: $\mathrm{UV}$ in $\mathrm{CHCl}_{3}$, and closed square: $\mathrm{PL}$ in $\mathrm{CHCl}_{3}$.

tively. Nevertheless, the effective $\pi$-conjugation length along the main chain is believed to extend because the imidazole moiety behaves as both proton donor and acceptor. The maximum $\pi$-conjugation is limited to the segment containing two imidazolyl and one phenyl rings in PImPho because there is large twist between two aromatic rings without intramolecular hydrogen bonding bridge (Figure 7, left). While the maximum $\pi$-conjugation could be elongated to the segment containing many aromatic rings in PImPh65 by releasing the twist, for example, two imidazolyl and two phenyl rings (Figure 7, right). The precision control of the regioregularity and the complete conversion of the deprotection are under investigation, which will clearly make out our hypothesis.

The UV and PL spectra of PImPh65 were subsequently obtained in various solvents having the different polarity. By increasing the solvent polarity in the order of $\mathrm{CHCl}_{3}<$ THF $<$ DMF, the spectra demonstrated hypsochromic and hypochromic shifts which also indicated the presence of intramolecular hydrogen bonding in PImPh65 especially in a less polar $\mathrm{CHCl}_{3}$ solution (Figure 8). In a highly polar solvent such as DMF, the intramolecular hydrogen bonding is supposed to be destabilized or destroyed. Since the UV absorption maximum wavelength of PImPh65 in a DMF solution was detected at the shorter wavelength region (357 nm) than that of PImPh0 in a $\mathrm{CHCl}_{3}$ solution $(372 \mathrm{~nm})$,

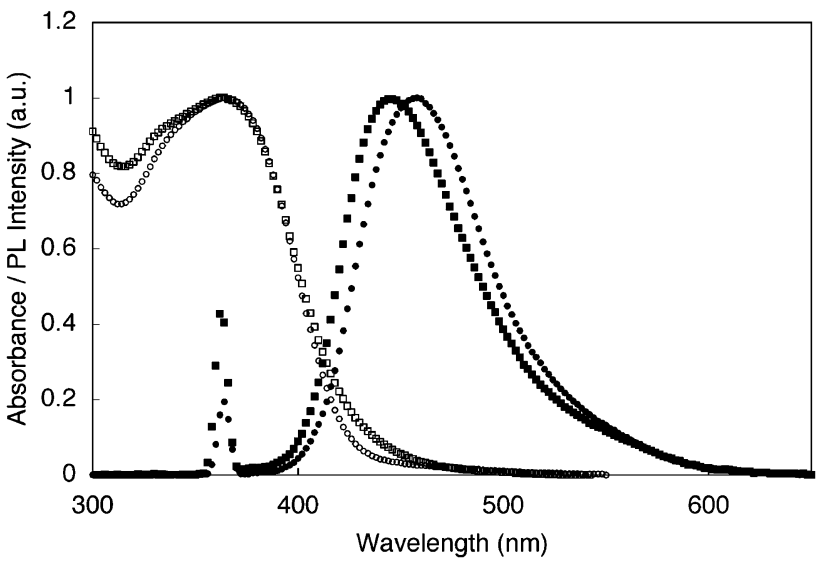

Figure 9. UV and PL spectra of PImPh65 by addition of $\mathrm{NaOH}$ (100 equiv. relative to acidic protons) in $\mathrm{THF} / \mathrm{H}_{2} \mathrm{O}(100 / 1$ in volume ratio) $\left(10^{-5} \mathrm{M}\right)$. Opened circle: UV without $\mathrm{NaOH}$, closed circle: $\mathrm{PL}$ without $\mathrm{NaOH}$, opened square: UV with $\mathrm{NaOH}$, and closed square: PL with $\mathrm{NaOH}$.

not only the $\mathrm{O}-\mathrm{H} \cdots \mathrm{N}=\mathrm{C}$ hydrogen bonding but also the $\mathrm{N}$ $\mathrm{H}$-.. O-R hydrogen bonding is probably cleaved. The influence of solvent polarity upon the optical spectra was small for PBImPh65.

An aqueous solution of $\mathrm{NaOH}$ was added to a THF solution of PImPh65 while keeping the concentration of $\mathrm{H}_{2} \mathrm{O}$ below $1 \%$. The addition of equivalent $\mathrm{NaOH}$ to the sum of acidic protons, i.e., the hydroxyl and amino protons, could not bring about the recognizable spectral change. In the presence of excess $\mathrm{NaOH}$ (100 equiv.), the UV spectrum showed a shoulder at $334 \mathrm{~nm}$ and the PL spectrum blue shifted by $13 \mathrm{~nm}$ (Figure 9). These results indicate that the intramolecular hydrogen bonding formed in PImPh65 is relatively stable but is collapsed with excess base. In sharp contrast, Yamamoto et al. reported the red-shift of the PL spectrum by adding $\mathrm{NaOH}$ to a solution of benzimidazole-containing conjugated polymer. $^{7 \mathrm{~b}}$ They concluded that the reduction of steric hindrance between the benzimidazole and thiophene rings resulted in the bathochromic shift. The difference of spectrum shifts observed in these two materials may be originated from the presence of intramolecular hydrogen bonding, which is the distinguished character of PImPh65. PImPh0 without the phenolic hydroxyl group also showed a similar shift of PL spectrum by adding $\mathrm{NaOH}$, but the magnitude of shift was rather small as much as $2 \mathrm{~nm}$. 
up

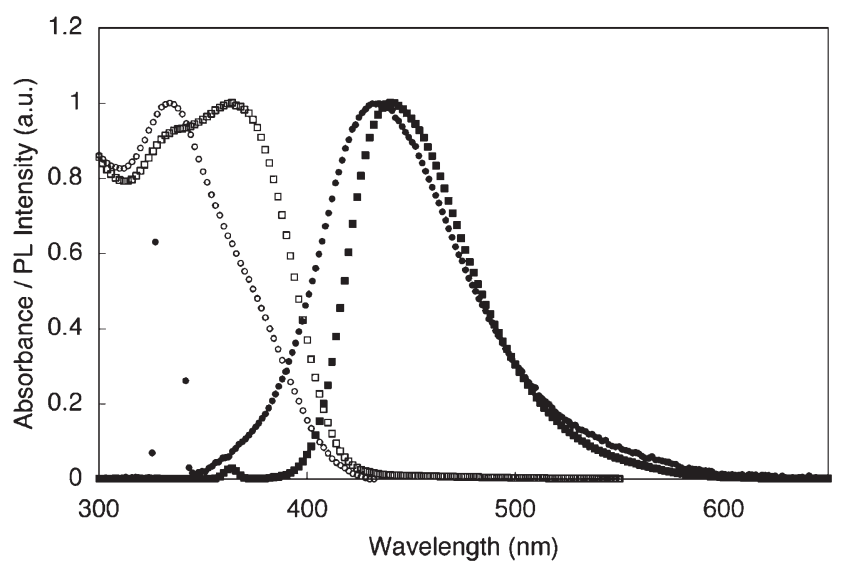

down

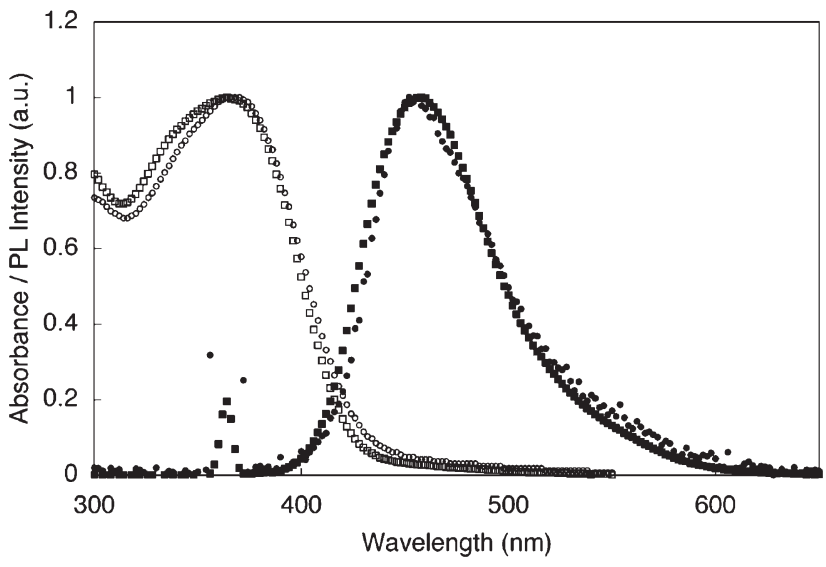

Figure 10. UV and PL spectra of PImPh0 (up) and PImPh65 (down). Opened circle: UV in THF solution, closed circle: PL in THF solution, opened square: UV in thin film, and closed square: PL in thin film.

Finally, thin films of PImPh0 and PImPh65 were obtained by spin coating a toluene/THF (1:1 in volume) solution $(6 \mathrm{mg} /$ $\mathrm{mL}$ ) on a quartz plate, in which THF was combined to get films with a good quality. The absorption and emission maximum wavelengths of PImPh0 blue shifted from the solution to film state by $30 \mathrm{~nm}$ and $7 \mathrm{~nm}$, respectively (Figure 10, up). The maximum absorption wavelength of PImPh0 in a film was $334 \mathrm{~nm}$, which was observed as a smooth shoulder peak in a THF solution, and this absorption band might be characterized to the $\pi-\pi^{*}$ transition of the segment unable to form the intramolecular hydrogen bonding. Thus the hypsochromic shifts are supposed to stem from the collapse of intramolecular hydrogen bonding, as previously reported by Moigne et al. for a conjugated polymer forming the randomly distributed intramolecular hydrogen bonding. ${ }^{8 \mathrm{~b}}$ On the other hand, the UV and PL spectra of PImPh65 demonstrated ignorable shifts, which suggests that the intramolecular hydrogen bonding formed in PImPh65 is relatively stable and the oligomer chain adopts a non-planar conformation to prevent the intermolecular $\pi-\pi$ stacking (Figure 10, down). The UV and PL spectra of
PBImPh65 demonstrated red shifts by changing from a solution to a spin-coat film, normally observed for other $\pi$ conjugated planar molecules (Figure not shown here).

\section{CONCLUSIONS}

Two kinds of conjugated oligomers containing imidazole (PImPh0) and benzimidazole moieties (PBImPh0) were synthesized, which had protected phenolic hydroxyl groups. The low molecular weights $\left(M_{\mathrm{n}}\right)$ were ascribed to the deactivation of the palladium catalyst by the coordination of the imidazole unit. The relative coupling direction of two monomer components (regioregularity) in the repeating unit was found to be random, as confirmed by the ${ }^{1} \mathrm{H}$ NMR spectra, because the chemical reactivity of two boronic acids was almost same. The phenolic hydroxyl group was subsequently deprotected by the catalytic hydrogenation using $\mathrm{Pd}-\mathrm{C} / \mathrm{H}_{2}$ system, although the conversion was up to $65 \%$. The decreased solubility of oligomers indicates the formation of intramolecular hydrogen bonding.

The absorption and emission maximum wavelength of PImPh0 in a THF solution was observed at $364 \mathrm{~nm}$ and $441 \mathrm{~nm}$, respectively, which showed a bathochromic shifts as compared with PBImPh0 $(\lambda \mathrm{abs}=349 \mathrm{~nm}$ and $\lambda \mathrm{em}=419$ $\mathrm{nm}$ ) bearing the same protected hydroxyl group. By deprotecting the hydroxyl group, both the UV and PL spectra red shifted, that is, the absorption and emission maximum wavelengths of PImPh65 were observed at $372 \mathrm{~nm}$ and $458 \mathrm{~nm}$, respectively. The fluorescent quantum yield dropped down from 0.40 (PImPh0) to 0.09 (PImPh65). Conversely, there was no detectable red-shift in the PL spectrum of PBImPh65 from that of PBImPh0. By increasing the solvent polarity in the order of $\mathrm{CHCl}_{3}<\mathrm{THF}<\mathrm{DMF}$, the spectra of PImPh65 demonstrated hypsochromic and hypochromic shifts. The addition of an excess amount of $\mathrm{NaOH}$ to a THF solution induced a blue-shift of the PL spectra of PImPh65. PImPh0 also showed a similar shift of the PL spectra by adding $\mathrm{NaOH}$, but the magnitude of shift was small $(2 \mathrm{~nm})$. The absorption and emission maximum wavelengths of PImPh0 in a film state blue shifted compared to a solution state by $30 \mathrm{~nm}$ and $7 \mathrm{~nm}$, respectively. On the other hand, the UV and PL spectra of PImPh65 demonstrated ignorable shifts. These results suggest that two intramolecular hydrogen bondings are formed and the oligomer chain adopts a non-planar conformation in PImPh65.

Received: February 12, 2008

Accepted: March 24, 2008

Published: May 21, 2008

\section{REFERENCES}

1. a) J. H. Burroughes, D. D. C. Bradley, A. R. Brown, R. N. Marks, K. Mackay, R. H. Friend, P. L. Burn, and A. B. Holmes, Nature, 347, 539 (1990).

b) K. Yoshino, K. Tada, and M. Onoda, Jpn. J. Appl. Phys., 33, L1785 (1994).

2. a) Z. Bao, A. Dodabalapur, and A. J. Lovinger, Appl. Phys. Lett., 69, 
4108 (1996).

b) H. Sirringhaus, N. Tessler, and R. H. Friend, Science, 280, 1741 (1998).

3. a) C. W. Tang, Appl. Phys. Lett., 48, 183 (1986).

b) J. J. M. Halls, C. A. Walls, N. C. Greenham, E. A. Marseglia,

R. H. Friend, S. C. Moratti, and A. B. Holmes, Nature, 376, 498 (1995).

4. a) Q. Zhou and T. M. Swager, J. Am. Chem. Soc., 117, 12593 (1995). b) J. W. Hong, B. S. Gaylord, and G. C. Bazan, J. Am. Chem. Soc., 124, 11868 (2002).

5. a) T. Yamamoto, T. Maruyama, Z.-H. Zhou, T. Ito, T. Fukuda, Y. Yoneda, F. Begum, T. Ikeda, S. Sasaki, H. Takezoe, A. Fukuda, and K. Kubota, J. Am. Chem. Soc., 116, 4832 (1994).

b) M. J. Marsella, D.-K. Fu, and T. M. Swager, Adv. Mater., 7, 145 (1995).

c) K. D. Ley, C. E. Whittle, M. D. Bartberger, and K. S. Schanze, J. Am. Chem. Soc., 119, 3423 (1997).

6. J. Catalan, R. M. Claramunt, J. Elguero, J. Laynez, M. Menendez, F. Anvia, J. H. Quian, M. Taagepera, and R. W. Taft, J. Am. Chem. Soc., 110, 4105 (1988).

7. a) T. Yamamoto, K. Sugiyama, T. Kanbara, H. Hayashi, and H. Etori, Macromol. Chem. Phys., 199, 1807 (1998).

b) I. Nurulla, A. Tanimoto, K. Shiraishi, S. Sasaki, and T. Yamamoto, Polymer, 43, 1287 (2002).
8. a) Y. Yao, J. J. S. Lamba, and J. M. Tour, J. Am. Chem. Soc., 120, 2805 (1998).

b) M. Moroni, J. L. Moigne, T. A. Pham, and J.-Y. Bigot, Macromolecules, 30, 1964 (1997).

c) C. Baskar, Y.-H. Lai, and S. Valiyaveettil, Macromolecules, 34, 6255 (2001).

d) A. P. Monkman, L.-O. Pålsson, R. W. T. Higgins, C. Wang, M. R. Bryce, A. S. Batsanov, and J. A. K. Howard, J. Am. Chem. Soc., 124, 6049 (2002).

9. a) A. R. Sanford and B. Gong, Curr. Org. Chem., 7, 1649 (2003).

b) B. Gong, Chem. Eur. J., 7, 4336 (2001).

c) I. Huc, Eur. J. Org. Chem., 17 (2004).

d) A. E. Rowan and R. J. M. Nolte, Angew. Chem., Int. Ed., 37, 63 (1998).

10. A. Ikezaki and M. Nakamura, Inorg. Chem., 41, 6225 (2002).

11. Z. Dominguez, T.-A. V. Khuong, H. Dang, C. N. Sanrame, J. E. Nunez, and M. A. Garcia-Garibay, J. Am. Chem. Soc., 125, 8827 (2003).

12. Y. Fu, S. Laurent, and R. N. Muller, Eur. J. Org. Chem., 2002, 3966.

13. K. Thede, N. Diedrichs, and J. P. Ragot, Org. Lett., 6, 4595 (2004).

14. M. Forster, K. O. Annan, and U. Schelf, Macromolecules, 32, 3159 (1999).

15. M. Vetrichelvan and S. Valiyaveettil, Chem. Eur. J., 11, 5889 (2005). 